\title{
La clau de tot plegat: la importància de "què" ensenyar a l'aula de ciències
}

\author{
Digna Couso Lagarón (digna.couso@uab.cat) \\ CRECIM i Departament de Didàctica de la Matemàtica i les Ciències Experimentals de la UAB
}

Quan es parla d'innovació a l'ensenyament de les ciències hom es refereix, generalment, a formes noves d'organitzar els "com" ensenyar o a nous "per a què" ensenyar. Generalment, però, la innovació didàctica no es relaciona amb canviar o millorar el "què ensenyar", es a dir "què" de ciència i "quina" ciència fer viure a l'aula. En aquest article volem plantejar al lector que problematitzar el contingut és la clau d'un ensenyament de les ciències més adient, $i$ que moltes vegades bones propostes de "com" $i$ "per a què" acaben sent deficitàries precisament per aquesta manca de problematització i tria adequada del contingut, de "què" ensenyar. Com a exemple discutirem les limitacions del conegut enfocament indagatiu per l'ensenyament de les ciències o IBSE, que en el nostre país ha tingut ressò sobretot en l'ensenyament per projectes a primària. La nostre proposta és compartir amb els docents la necessitat de començar per pensar molt bé "quina versió" de les idees científiques volem que els alumnes utilitzin per pensar, fer i parlar, entenent que aquesta "versió" ha de ser adient per actuar i prendre decisions en les problemàtiques que li proposem $i$ alhora ha de ser una fita en el camí o progressió de les seves idees cap a idees científiques clau, cada cop més sofisticades i complertes.

Paraules clau: Indagació, modelització, educació primària.

When talking about innovation in science teaching, we generally refer to new ways of organizing "how to teach" or "why teaching" science. However, innovation is not usually related to changes into "what to teach", it is, "which" science and "how" to make students live science in classroom. In this article, we expect to propose that the key for a suitable science education is how the content is problematized. We also want to highlight that most of educational proposals in science instruction become deficient because the lack of this content problematization. As an example, we will discuss about the limits of "Inquiry based science education approach" (IBSE), which has played an important role in our country, especially in project-based education in primary school. We expect to share with teachers the need for thinking in depth "which version" of scientific ideas should use our students if we want to make them thinking, making and talking about it. We assume that this "version" of scientific ideas must be adapted for students' acting and decision-making in the proposed situations, and we also assume that it must become a milestone on the progression of students' ideas, which have to increasingly progress to become more sophisticated and complete.

Keywords: Inquiry, modelling, primary school.

Quan es parla d'innovació a l'ensenyament de les ciències hom es refereix, generalment, a formes noves d'organitzar els "com" ensenyar o a nous "per a què" ensenyar. Per exemple, es parla de models d'ensenyament i aprenentatge més experi- encials o pràctics, alumnes més participatius i actius, avaluació més formativa, gestió d'aula més cooperativa, plantejaments en contextos més propers, etc. $\mathrm{O}$ es discuteix sobre si l'objectiu es l'assoliment de la comprensió o de la competència, 
o què vol dir exactament ser competent amb el coneixement científic (ser capaç de resoldre problemes?, prendre decisions informades? d'actuar?...). Generalment, però, la innovació didàctica no es relaciona amb canviar o millorar el "què ensenyar", es a dir "què" de ciència i "quina" ciència fer viure a l'aula. De fet, algun lector por estar ara mateix fins $i$ tot estranyat de que pugui tenir sentit parlar de "millorar" els continguts: és que no són els que són, els que diu el currículum?. En aquest article, però, volem plantejar al lector que problematitzar el contingut és la clau d'un ensenyament de les ciències més adient, i que moltes vegades bones propostes de "coms" i "per a quès" acaben sent deficitàries precisament per aquesta manca de problematització i tria adequada del contingut, de "què" ensenyar.

\section{UN EXEMPLE DE BONES INTENCIONS: L'ENSENYAMENT DE LES CIËNCIES COM A INDAGACIÓ.}

Un exemple de model didàctic innovador que proposa "coms" i "per a quès" interessants però que genera molta crítica en la didàctica erudita per no donar importància al contingut és el conegut IBSE o "ensenyament de les ciències com a indagació". Tot i que en les nostres aules no se'n parla tant amb aquestes sigles o nom en concret, idees del mateix han permeat l'aula de ciències, en particular de primària, en els darrers anys. En són exemple estratègies didàctiques inspirades en el cicle de les " 5 E's" de R. Bybee (Engage, Explore, Explain, Elaborate, Evaluate), com ara començar els projectes despertant l'interès o involucrant l'estudiant (sovint amb l'interès dels estudiants com inici dels projectes) o fer-los explorar i investigar de forma més o menys autònoma sobre el tema de treball. Són activitats comunes, en aquest sentit, les cerques a Internet i llibres, però també les observacions i realització d'activitats pràctiques i fins $i$ tot experiments de forma més lliure que en el treball pràctic tradicional.

A la literatura en didàctica de les ciències, les propostes d'ensenyament de les ciències com indagació o IBSE (Inquiry-Based Science Education) han guanyat terreny en els darrers anys. Fomentades inicialment des de l'àmbit polític-administratiu en EEUU amb la publicació dels estàndards de ciències (NRC 1996), el seu aterratge a Europa s'associa a la publicació del controvertit informe Science Education Now (Rocard, 2007), que la proposa com estratègia docent privilegiada. La conseqüència (arrel del canvi en les directrius de finançament) ha estat una proliferació de projectes IBSE (POLLEN, FIBONACCI, PATHWAY, PRI-
MAS, COMPAS, etc.) que fan disponible a Internet una enorme varietat d'activitats i propostes.

Tot i la seva diversitat, des del nostre punt de vista (Couso, 2014) les diferents propostes IBSE tenen en comú tres aspectes:

1) La voluntat de plantejar un escenari d'ensenyament-aprenentatge d'indagació el més autèntica possible (anàleg al d'una recerca científica real), on els alumnes es plantegen preguntes investigables $\mathrm{i}$ obtenen les seves pròpies dades (generalment de forma pràctica, a partir d'observacions o experiments) o fan servir dades disponibles. Per fer-ho, generalment s'organitza la instrucció en etapes o fases, seguint un cert cicle que pretén emular la investigació científica real.

2) Donar molta importància a la actitud i motivació dels i les estudiants, atorgant-los un paper molt actiu i protagonista. En general se'ls hi proposa treballar en grup i se'ls hi dóna molta més autonomia i capacitat de decisió i elecció que en una aula tradicional, en particular quan les indagacions són obertes $i$ els estudiants escullen fins $i$ tot la temàtica a treballar.

3) Per contraposició a aquests punts anteriors, emfatitzar la importància d'un paper més passiu del professor, basat en la idea de "guia" i "facilitador" de la indagació, així com aprenent amb els alumnes de les idees o del coneixement que es genera en les indagacions.

Tenint en compte l'atractiu d'aquestes idees, podria resultat sorprenent que la metodologia IBSE hagi rebut i continuï rebent importants critiques dins de l'àmbit de la didàctica (Ogborn, 2012; Viennot, 2011; Hodson, 2014), així com que ens plantegem en aquestes línies una reflexió de fons sobre aquesta i altres propostes que només es centren en com o per a què ensenyar.

Per ajudar a entendre quins són els problemes que associem a l'ensenyament de les ciències com a indagació proposem classificar les diverses propostes IBSE en un espai en tres dimensions (Couso, 2014) respecte quines habilitats indagatives estimulen, quin model de ciència i de l'activitat científica comuniquen i quina importància hi donen al contingut conceptual (Figura 1). Si ens mirem l'eix vertical de la Figura 1, veurem que les activitats d'aula de tall indagatiu poden estar situades en un espectre que va des d'activitats de tipus merament tècnic-manipulatiu, centrades en el desenvolupament d'habilitats procedimentals tals com mesurar, observar, fer un gràfic, etc. fins a activitats orientades al desenvolupament de destreses cognitivo- 
discursives de la recerca en ciències, com la repetició de les mesures per tal de minimitzar l'error, el control de variables per a determinar relacions d'influència, l'ús de proves per concloure i la comunicació de resultats, entre altres (Millar, Lubben, Gott i Duggan, 1995).

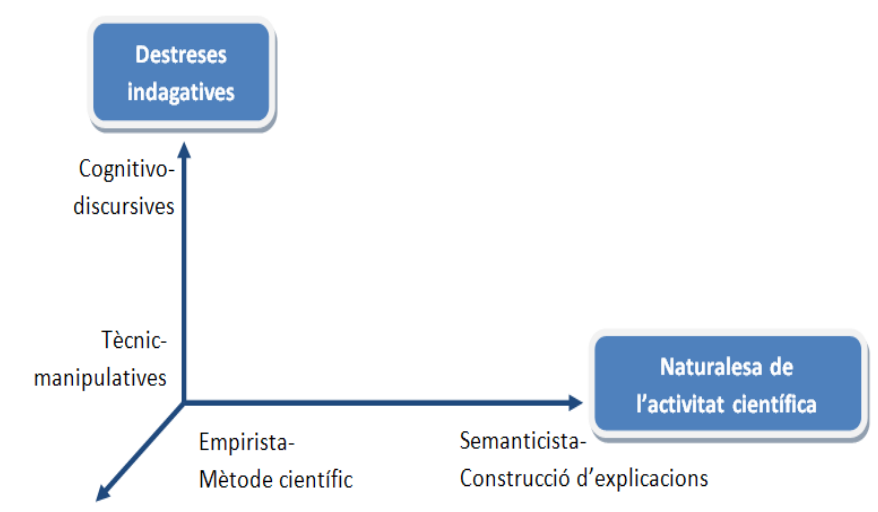

Contingut

conceptual

Figura 1. Dimensions per caracteritzar una proposta d'aula IBSE

De forma anàloga, en l'eix horitzontal de la Figura 1 també es representa, en un extrem, les activitats d'indagació que comuniquen una imatge de l'empresa científica de tall empiricista, dominades per l'aplicació del "mètode científic" entès com a constructe cultural icònic de passos ben establerts (observar, plantejar una pregunta, desenvolupar una hipòtesis, conduir un experiment, analitzar dades, extreure conclusions, generar noves preguntes) i arrel empírica orientat a "descobrir" els conceptes, lleis o teories científiques a l'aula (Windschitl, Thompson, \& Braaten, 2008). En l'altre, les activitats d'indagació reflecteixen les noves visions de la naturalesa del coneixement i l'empresa científica, on l'activitat científica clau és "el desenvolupament d'explicacions basades en proves sobre com funciona el mon" (Giere, 1991). En aquest sentit, es dóna importància a la cognició i el discurs (el raonament, l'argumentació) en l'activitat científica real (i escolar), on l'observació i interrogació del fenomen es realitzen de maneres diverses i estan al servei de les idees i de la voluntat semàntica (que no demostrativa) de la ciència: la voluntat de construir significats.

Moltes de les activitats IBSE disponibles, malauradament, es troben tant respecte el tipus de destreses en les que es centren com respecte la naturalesa de la ciència que comuniquen, a prop del origen d'aquest espai bi-dimensional. En són

exemple, sorprenentment, fins i tot activitats indagatives paradigmàtiques que es proposen com exemplars en diferents formacions i projectes IBSE (veure Figura 2). En analitzar-les, veiem que estem davant d'indagacions "naïf" que plantegen tres problemes fonamentals.

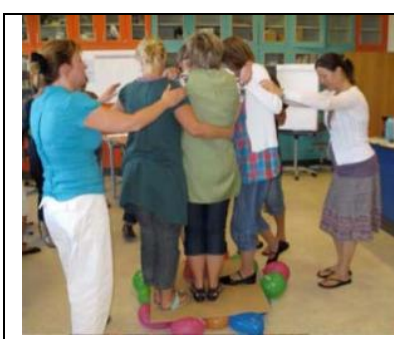

En un curs de formació de docents en exercici sobre IBSE, ofert en el marc del projecte Metodelab (Dinamarca), es planteja a un grup de professors de primària investigar quin és el mínim nombre de globus que fan falta per a sostenir a tres professors sobre una plataforma. Els professors fan les seves prediccions, plantegen hipòtesis, realitzen l'experiment, prenen dades, etc. Aquesta activitat es fa servir per ensenyar als docents el "mètode científic", així com a fer prediccions, plantejar hipòtesis, dissenyar experiments, etc. Font: Extret de la conferència plenària de Sarah Tougaart, Simposi ENCIENDE de COSCE, Caixaforum Madrid, 2013

Quadre 1: Exemples d'activitats IBSE reals que considerem serveixen només per ensenyar destreses indagatives

Primer: Plantejar activitats d'indagació que només serveixen per aprendre formes epistemològica i didàcticament pobres d'indagar. $O$ el que es el mateix, indagar només per aprendre a indagar (plantejar preguntes investigables, triar variables, etc.) com si això fos tot el que s'ha d'aprendre a ciències, i a sobre fer-ho malament. En aquestes activitats, la naturalesa de la ciència que es comunica es profundament positivista i empirista, l'èmfasi es posa en el desenvolupament de destreses indagatives que solen ser de baix perfil cognitiu, més sovint procediments $\mathrm{i}$ tècniques manipulatives que destreses cognitiu-discursives. Per exemple, en la implementació de l'activitat dels rellotges de sorra s'acostuma a posar l'èmfasi en el fet que els alumnes aprenguin a mesurar amb el cronòmetre o representar les dades en un gràfic de barres. Sense subestimar la importància que els alumnes apren- 
guin aquests procediments $i$ tècniques, en particular a primària, l'èmfasi que moltes activitats indagatives donen a les mateixes no és comparable amb el que es dóna a destreses indagatives d'ordre superior, com controlar variables, planificar procediments o interpretar patrons en les proves, que són molt més difícils d'aprendre i s'han de treballar en cada oportunitat. En el nostre exemple, significaria preocupar-se de que els alumnes entenguin, per exemple, la necessitat de controlar l'experiment (per exemple, que com no podem aconseguir donar la volta als tres rellotges alhora per comparar-los, mesurarem i compararem el que triga cada un d'ells).

Segon: Avaluar la qualitat de la docència en base a la motivació i activitat dels i les estudiants, confonent estar actiu físicament amb estar motivat $\mathrm{i}$ actiu intel-lectualment. En concret, resulta preocupant la relació directa que s'estableix entre IBSE o altres metodologies similars (projectes, etc) i el concepte de "ciència divertida", que sovint s'utilitza per justificar i jutjar la qualitat de les propostes. Per preocupant que sigui el contrari (que els alumnes s'avorreixin fent ciències), no es pot confondre l'alumne divertit i actiu físicament (que "potineja", fa assaig $i$ error, etc.) amb un alumne involucrat intel-lectualment (que pensa, es pregunta, prova amb sentit, analitza les seves observacions, reflexiona etc.). En paraules d'Ogborn (2012), la ciència es basa en "pensament lent", es a dir, pensament producte d'esforçar-se i de posar-s'hi a pensar intencionadament, i es caracteritza per una disposició crítica, al considerar i avaluar alternatives (en contraposició al pensament ràpid, fàcil però crèdul $\mathrm{i}$ aproximat). Estem d'acord amb l'autor en que l'autentica motivació de l'alumne prové de d'experiències d'aplicació amb èxit del pensament lent.

Tercer: Atorgar un paper secundari al professor i a les estratègies docents, que es presenta 0 s'entén com un facilitador i guia que "promou i deixa fer". Si bé coincidim en pensar que resulta una millora educativa substancial que el professorat abandoni posicions centrades en ell mateix (en les seves explicacions, en el seu discurs, etc.) per centrar-se en els alumnes (les seves idees, les seves formes d'expressar-les), massa propostes IBSE exageren i tergiversen aquesta recomanació prenen una postura de "mans fora" per tal de deixar als alumnes "descobrir" la ciència per sí mateixos (Holliday 2004). Per exemple es reporta sovint com a positiu que els alumnes puguin escollir lliurement allò que volen estudiar encara que això impliqui que els professors "no sàpiguen" on els porta la indagació. Tal i com tan encertadament argumenten
Garriga, Pigrau i Sanmartí (2012) respecte als projectes en primària, molt sovint els temes que els alumnes escullen només serveixen per satisfer una curiositat inicial (generalment fortament mediatitzada), però difícilment per construir idees potents de la ciència, que els serveixin per analitzar i entendre altres entorns i situacions (que es puguin transferir) ni que els serveixin per actuar de forma responsable en el món (que puguin aplicar amb valors). D'altre banda, i d'acord amb meta-recerques sobre metodologies d'ensenyament, els estils docents "activadors" o "agents de canvi" (que donen feedback productiu, que ensenyen estratègies metacognitives,...) estan relacionats amb millors resultats que aquells merament "facilitadors" (Hattie, 2008).

\section{COM DĖIEM, LA CLAU ESTÀ EN EL QUĖ ENSENYAR!}

En l'arrel de les anteriors critiques epistemològiques i didàctiques a l'ensenyament IBSE està el fet que, com la majoria de les innovacions educatives, els plantejaments IBSE ignoren la importància del què ensenyar. En el cas de l'IBSE, la desconnexió amb el món de les idees, la teoria i el coneixement científic és notable, tal i com es pot veure en els exemples suposadament "exemplars" del Quadre 1 , el contingut científic conceptual a aprendre és nul. Darrera aquest fet està una confusió comuna en algunes propostes IBSE: confondre que les preguntes que es plantegen a l'aula IBSE siguin investigables (el fet que es puguin respondre amb proves) amb el fet que siguin científiques (que es puguin relacionar aquestes proves amb un concepte o idea científica clau).

$\mathrm{Hi}$ ha altres exemples, però, on el tema escollit per a la indagació a l'aula és aparentment més científic (flotabilitat, nutrició,...) però tot i així la manca de reflexió sobre el contingut i en quina "versió" treballar-lo fa que no constitueixin bons contextos d'ensenyament-aprenentatge on els alumnes puguin construir idees potents de la ciència (les idees clau, per exemple, de Harlen et al. (2010)), per dos motius principals.

El primer és que quan s'imposa que el treball pràctic ha de ser el centre de l'activitat, sovint es limita l'ensenyament a la realització d'experiments paradigmàtics que "van bé". Es a dir, experiments que són prou senzills per poder fer-se amb materials casolans, en un temps prudencial, de forma quasi-autònoma pels alumnes $i$ dels quals s'obtenen dades que permeten concloure directament les idees que es volen treballar. A banda de la pobresa epistemològica que impliquen aquests 
requisits per la tria d'experiments, també hi ha greus problemes didàctics. D'acord amb Viennot (2011), aquesta forma de fer redueix els continguts de l'ensenyament de les ciències a allò que es pot treballar en uns quants experiments senzills de control de variables plantejats de forma ritual. A banda, en no discutir "perquè es plantegen com es plantegen" aquests experiments en pro de la seva simplicitat i de que surtin bé, molt sovint són erronis. L'autora posa com a exemple els experiments típics de flotabilitat en l'aire, en els quals no se sol tenir en compte que a més de pes, hi ha una força ascensional que tindria una enorme influència si no peséssim amb un recipient rígid (volum fix).

En segon lloc, perquè tot i que en algunes propostes IBSE existeix una fase, etapa o moment dedicat a la construcció d'explicacions per part dels alumnes, tal i com hem discutit en un altre lloc (Simarro, Couso i Pintó, 2009), aquestes explicacions acostumen a ser "locals", es a dir explicacions directament derivades o que es poden inferir de les dades (per exemple, que hi ha materials que reflecteixen més el so que altres). Fins i tot quan es fa un esforç per sistematitzar aquestes explicacions de manera que es construeixi un model (una representació que ens serveixi per predir i explicar), aquests models només poden ser de caràcter empíric, és a dir, models que descriuen patrons o regularitats inferides de les dades. Un exemple serien quines propietats físiques macroscòpiques, como ara alta densitat i rigidesa o baixa porositat, s'associen als materials reflectors acústics (Hernández, Couso \& Pintó, 2014). Aquest model de reflector acústic, però, no interpreta perquè aquestes propietats fan que el material reflecteixi el so. Per poder construir models teòrics o interpretatius no podem basar-nos únicament en les dades obtingudes de l'experimentació, no per les limitacions inherents a l'experimentació en una aula, sinó per limitacions epistèmiques. Com constructe cognitiu i semàntic, no es pot induir un model o teoria. Coincidim amb Viennot (2011) en considerar que, a causa d'això, l'ensenyament IBSE no permet als alumnes obtenir explicacions prou satisfactòries perquè en cap cas poden derivar directament de l'experiència. Per exemple, comprovar que el període d'oscillació d'un pèndol simple no depèn de la massa no ens explica per què és així o en quins casos no ho seria.

Per si tot això fos poc, en moltes activitats IBSE la teoria i conceptes científics es presenten relegats a "complements" de l'experiència directa i es desproblematitza la seva relació amb les dades. Per exemple, a la guia didàctica del projecte POLLEN s'estableix que "Els estudiants no descobriran ni poden descobrir tot el que necessiten saber a tra- vés de la indagació. L'ús de fonts secundàries (Illibres, Internet, científics locals) en IBSE és important com servei de les exploracions dels estudiants, i no com un substitut de les mateixes " (POLLEN, 2009). Tal com assenyala Ogborn (2012), amb aquesta recomanació es relega el contingut conceptual a alguna cosa secundària que cal per ajudar en la indagació, que l'assisteix, i que a sobre no prové del docent. No obstant això, per a l'autor l'ordre seria invers. Com que els alumnes necessiten alguns recursos intel-lectuals per involucrar-se en una indagació amb sentit, la indagació hauria de servir per aprofundir en el que s'està aprenent (i no per a produir aprenentatge o per aclarir). Estem d'acord amb Ogborn (2012) en què això implica un repte per al professorat en particular en el context indagatiu: "El paper de l'activitat pràctica és provocar el pensament" (p.8); però canviar de manera de pensar només es pot fer a través del diàleg: expressant el que penso, comparant amb altres formes de pensar, argumentant quines idees són millors, consensuant.

\section{ALTRES FORMES DE TREBALLAR ELS CONTINGUTS O “ALTRES" CONTIN- GUTS?}

En l'essència de la nostre crítica (amb esperit constructiu!) als plantejaments IBSE, que d'altre banda podrien ser extensives a altres metodologies o modes pedagògiques, és l'intent de compartir amb els i les docents i dissenyadors/res de materials educatius la importància de problematitzar quins continguts volem ensenyar. En la majoria de propostes IBSE els autors/res no han escollit o adaptat la transposició didàctica (en termes de Chevallard) que consideren adequada. O dit d'una forma més entenedora, no han escollit la versió de la idea científica que consideren adient per als seus alumnes en aquest nivell concret. Aquesta "idea científica escolar", seguint la teoria dels continguts de Izquierdo (2005), és la forma en la que volem que els alumnes entenguin un concepte, que és adequada $i$ assequible en cada moment de l'aprenentatge i alhora, possibilita seguir construint versions més sofisticades de la mateixa al llarg de l'escolaritat. Per exemple, associar el canvi de moviment dels objectes a empentes i estirades que "els hi fem" o "es fan" entre ells és adient per als cicles inicial i mitja de primària, mentre que a la secundària voldríem que comencin a entendre les forces com la forma en la que conceptualitzem (com entenem) la interacció que es dóna entre els objectes, i que aquestes interaccions tenen més o menys efecte en el seu estat de moviment segons la resistència a canviar de moviment que tinguin (la 
seva inèrcia o massa inercial). Per ajudar a identificar quines són aquestes idees científiques i com les hem de fer progressar al llarg de l'escolarització alguns currículums internacionals s'organitzen en forma de mapes de progressió d'aquestes idees. En son exemple els currículums de USA o d'alguns estats d'Austràlia inspirats en el Atlas of Science $\mathrm{Li}$ teracy del projecte 2061 de la AAAS $(2001 ;$ 2007).

Problematitzar els continguts no només és important per tal d'ensenyar ( $\mathrm{i}$ aprendre) allò que toca (allò de ciències que és important que els alumnes dominin i siguin capaços de fer servir per pensar, parlar, fer i valorar en el seu dia a dia). La idea que volem compartir en aquestes línies és que al decidir adientment què hem d'ensenyar (el contingut) fixem una mica (o reduïm els graus de llibertat) de com fer-ho adientment a l'aula (la metodologia). Per exemple, en la majoria de propostes IBSE els experiments sobre flotabilitat són un clàssic. Segons per a quins nivells es proposin, en general s'espera que alumnes experimentin més o menys lliurement la flotabilitat d'objectes de diferents mides, materials i de vegades formes $i$ indueixin unes certes conclusions considerades "encertades", com ara que la flotabilitat depèn del tipus de material de l'objecte però no de la seva mida o pes; de si té aire o no a dins; o inclús de la densitat del material relativa al fluid. En el millor dels casos (una bona activitat ben planificada per arribar a aquestes conclusions) tindríem un model descriptiu del que succeeix (sura perquè la seva densitat és menor que la de l'aigua) però no interpretatiu de perquè succeeix (per què, si la seva densitat és menor, sura?, què ho fa surar?). I en cap cas es podria entendre ni relacionar directament aquest fet amb el principi d'Arquímedes, ja que ni necessàriament s'ha experimentat l'empenta de l'aigua, ni aquesta es pot relacionar fàcilment amb la densitat.

Existeixen, però, altres formes de transposar didàcticament (d'entendre, d'adaptar) el concepte de flotabilitat a l'aula que facilitarien la construcció d'un model teòric més interpretatiu, connectat amb les grans idees de la ciència (com ara que els objectes interaccionen entre sí i s'empenyen/estiren) que ens dirigirien cap a un altre tipus d'activitat experimental amb el fenomen. Ogborn (2012) proposa començar per treballar la idea de com costa "fer un forat" a l'aigua, per exemple, prement contra la superfície de l'aigua amb un got de plàstic lleuger (veure Figura 2). Què passa quan ho fem? Notem que l'aigua ens empeny. Com podem fer que ens empenyi menys? Si anem omplint el got amb aigua, ens empeny menys. Si l'omplim pràcticament fins a dalt del tot, ja no l'hem d'empènyer. Es a dir, que el que s'ha d'empènyer per fer un forat a l'aigua d'una certa mida (volum) és lo mateix que pesa aquest volum d'aigua. O sigui el principi d'Arquímedes.
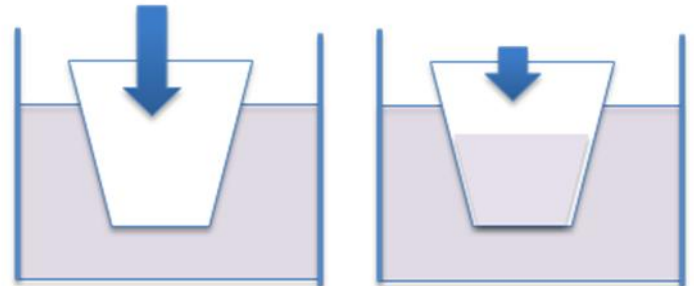

Figura 2: quant costa fer un forat a l'aigua? Afegint aigua veiem que "deixa de costar" justament quan omplim el got d'aigua fins al límit.

En la meva experiència com a formadora de mestres hem fet servir un raonament similar que ajuda a relacionar força (empenta) i densitat. Per fer-ho no només notem com costa fer un forat a l'aigua (introduir-hi un cert volum), sinó que també construïm la idea de que és així perquè l'aigua en el recipient, per cada "trosset" (volum) d'aigua que ens puguem imaginar, fa la força necessària per sostenir aquest volum d'aigua, que sinó cauria atret per la gravetat. Quan substituïm un cert volum d'aigua per un objecte qualsevol del mateix volum (fiquem un objecte allà on només hi havia aigua), pot passar que aquest nou objecte pesi més o menys que el que pesava el volum d'aigua que estava allà i que ara desplaça. Es a dir, pot passar que l'objecte pesi més o menys que si "fos" d'aigua. Si un objecte pesa més que si "fos d'aigua", la força resultant que fa l'aigua per sota l'objecte i que era prou per sostenir un volum d'aigua ara no és suficient per sostenir el mateix volum d'una altre cosa més pesant i s'enfonsa. Si pesa menys que si fos d'aigua, però, com la força que fa l'aigua per sota l'objecte és capaç d'aguantar el pes d'un volum d'aigua com l'objecte, l'aigua no només sosté l'objecte sinó que l'empeny cap amunt. Quan puja l'objecte? En anar pujant i començar a surar una part de l'objecte surt de l'aigua i ja no empeny (ja no està fent un forat a l'aigua). Per tant puja fins que la part de l'objecte enfonsada, si fos d'aigua, peses igual que tot l'objecte. La Figura 3 mostra alguns exemples de gràfics que utilitzem per compartir aquestes idees.

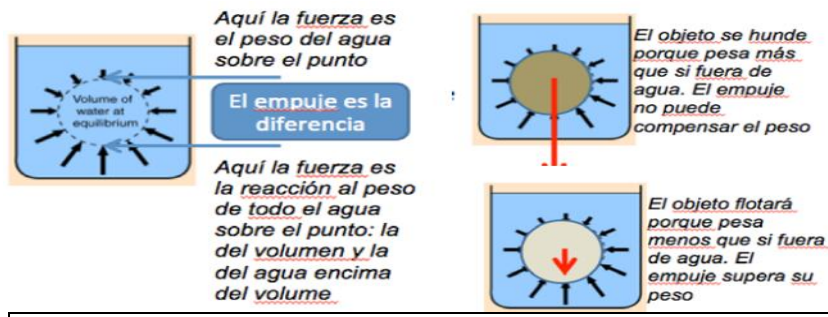

Figura 3: Explicació utilitzada per explicar en quins casos un objecte s'enfonsa o sura en un fluid. 
En els dos exemples esmentats, i a partir d'un diàleg ric (al voltant de preguntes focalitzades) i d'un raonament que s'inspira en i s'ajusta a (però no deriva de) l'observació del fenomen de la flotabilitat, es facilita la comprensió de la relació entre força d'empenta i densitat, perquè allò que fa que un objecte pesi més o menys que "si fos" d'aigua és que la seva densitat sigui major o menor a la de l'aigua. A més, aquest tipus de transposició didàctica o forma de treballar el concepte de flotabilitat a l'aula és més adequat per entendre la situació dinàmica (mentre l'objecte s'enfonsa o sura), permet entendre la flotabilitat en el marc d'una teoria central (la mecànica newtoniana) i també la relació amb altres conceptes (com la força normal, ja que l'empenta no deixa de ser una força normal exercida per un fluid).

L'exemple presentat per descomptat pot plantejar-se com una indagació als estudiants. No obstant això, creiem que l'important per comprendre com expliquem en ciència escolar el que passa (que uns objectes suren i altres no en un fluid, i que això depèn de la seva densitat relativa al fluid) depèn molt més de l'activitat mental que experimental dels alumnes. Per apropiar-se un model correcte de flotabilitat, han imaginar-se un volum d'aigua amb la forma d'un objecte real, o un objecte real "fet d'aigua"; s'han d'imaginar i dibuixar fletxes o altres representacions de les empentes i/o forces implicades; han d'explicar com ho entenen, escoltar com ho expliquen altres, reformular. Encara que l'experiència amb el fenomen és molt important i serveix per despertar l'interès, així com donar sentit a conceptes com a força d'empenta o volum, no es requereix necessàriament d'una indagació o investigació per aprofitar el potencial del contacte amb el fenomen per construir les idees. Finalment, i com hem dit, creiem que l'aspecte crucial que la didàctica de les ciències aporta és precisament la "forma d'entendre" en ciència escolar aquest fenomen, i les formes en què el professor pot ajudar l'alumne (inclosa la indagació, però no només ni predominantment aquesta) a construir aquesta forma d'entendre'l.

\section{ALGUNES IDEES PER FINALITZAR}

Malgrat les moltes dificultats i detalls crítics que cal superar perquè un ensenyament de les ciències basat en la indagació sigui didàctica i epistemològicament satisfactori, el moviment d'ensenyament de les ciències basat en la indagació ha suposat un important primer pas en el camí cap a la comprensió de la ciència escolar com la participació (i enculturació) en les pràctiques o formes de fer, pensar i ser de la comunitat científica (Jiménez-
Aleixandre, 2011). Encara que l'èmfasi que hem posat en els objectius epistemològics i en les pràctiques per a construir, comunicar i avaluar el coneixement científic conceptual fa que bona part de les propostes IBSE que analitzem siguin poc adequades, devem a aquest marc l'incentivar en els docents el desig de portar "activitat científica" a l'aula (encara que sigui de forma incompleta). Està per veure si els que advoquem per noves propostes d'ensenyament $i$ aprenentatge més acords amb una visió de ciència centrada en la construcció d'explicacions (models) som capaços de capitalitzar aquest interès inicial que li devem a les propostes IBSE. En particular, són aspectes preocupants la formació del professorat d'acord amb els reptes d'un ensenyament de les ciències com a pràctica científica i el aconseguir varietat de propostes centrades en la modelització tant per a l'aula de secundària com de primària.

Una darrera idea important és que no advocar per un ensenyament totalment $\mathrm{o}$ majoritàriament de tipus IBSE no significa no advocar per ensenyar a indagar, sinó més aviat el contrari. Independentment del model d'ensenyament i aprenentatge escollit, coincidim amb Ogborn (2012) en què aprendre a investigar és tan important per als nostres alumnes que en l'ensenyament ha de permetre en alguna ocasió el participar en una investigació realment genuïna. D'acord a l'autor això implica que el problema a investigar sigui modest, el temps dedicat llarg i el procés s'avaluï com a tal, i no per l'èxit que s'obtingui. En són un bon exemple d'això els projectes d'investigació de final del batxillerat. En aquestes situacions l'alumnat s'enfronta a una sèrie de dificultats que podrien mitigar si es realitzessin petites investigacions abans (Menoyo, 2013), ja que no només les destreses indagatives sinó també els valors i actituds (com la curiositat i l'interès per investigar) són educables (de Manuel, 2000). No obstant això, les indagacions rituals forçades per tal d'aprendre conceptes no són aquest context de recerca genuïna, sinó un "teatre" de l'activitat científica que la trivialitza profundament (Hodson 2014).

\section{REFERÈNCIES}

AAAS (2001/2007) Atlas of Science Literacy, Volumes 1 and 2. Project 2061

COUSO, D. (2014) (2014). De la moda de "aprender indagando" a la indagación para modelizar: una reflexión crítica. Actas del XXVI Encuentro de Didáctica de las Ciencias Experimentales. Huelva (Andalucía): 
http://uhu.es/26edce/actas/docs/conferencias/pd $\mathrm{f} / 26 E N C U E N T R O \_D C E-$

ConferenciaPlenarialnaugural.pdf

GARRIGA, N., PIGRAU, T., \& SANMARTí, N. (2012) Cap a una pràctica de projectes orientats a la modelització. Ciències, 21, 18-28

GIERE, R. N. (1991), Understanding Scientific Reasoning (3rd ed.), New York: Harcourt Brace Jovanovich.

HARLEN, W. (Ed) (2010) Principles and Big Ideas of Science Education, Hatfield: ASE

HATTIE, J. (2009) Visible Learning, A synthesis of over 800 meta-Analyses relating to achievement, (2nd. Edition), Routledge: New York.

HERNÁNDEZ, M.I., COUSO, D., PINTÓ, R. (2014) Analyzing students' learning progressions throughout a teaching sequence on Acoustic Properties of Materials with a modelbased inquiry approach. Journal of Science Education and Technology, 24 (2-3), 356-377.

HODSON, D. (2014). Learning Science, Learning about Science, Doing Science: Different goals demand different learning methods. International Journal of Science Education, 36(15), 25342553.

HOLLIDAY, W. G. (2004) A balanced approach to science inquiry teaching. In L. B. Flick \& N. G. Lederman (Eds.), Scientific inquiry and nature of science: Implications for teaching, learning, and teacher education. (pp.201-217) Dordrecht: Kluwer Academic Publishers

IZQUIERDO, M. (2005). Hacia una teoría de los contenidos escolares. Revista Enseñanza de las Ciencias, 23(1), 111-122.

JIMÉNEZ-ALEIXANDRE, M.P. (2011) Las prácticas científicas en la investigación y en la clase de ciencias. Ponencia plenaria de los XXV Encuentros de Didáctica de las Ciencias Experimentales de APICE. Santiago de Compostela. http://www.apicedce.com/sites/default/files/XXV\%20EDCE.pdf

NRC. (1996). The National Science Education Standars. Washington D.C.: National Academy Press.

MILLAR, R., LUBBEN, F., GOTT, R., \& DUGGAN, $S$. (1995). Investigating in the school science laboratory: conceptual and procedural knowledge and their influence on performance. Research Papers in Education, 9(2), 207-248.

OGBORN, J. (2012). Curriculum Development in Physics: Not Quite so Fast. Scientia in educatione 3(2), p. 3-15. (Article basat en la Conferència plenària del 03 de juliol de 2012, al The World Conference on Physics Education 2012, Istanbul,Turkey.

ROCARD, Y. (2007). Science Education Now, Report EU22-845, EU, Brussels: http://ec.europa.eu/research/sciencesociety/document_library/pdf_06/report-rocardon-science-education_en.pdf

SIMARRO, C., COUSO, D. \& PINTÓ, R. (2013). "Indagació basada en la modelització: un marc per al treball pràctic" Ciències, 25, 35-43

VIENNOT, L. (2011). Els molts reptes d'un ensenyament de les Ciències basat en la indagació: ens aportaran múltiples beneficis en l'aprenentatge? Ciències, 18, 22-36.

WINDSCHITL, M., THOMPSON, J., \& BRAATEN, M. (2008). Beyond the Scientific Method: ModelBased Inquiry as a New Paradigm of Preference for School Science Investigations. Science Education, 92(5), 941-967. 